Territorios 36 / Bogotá, 2017, pp. 87-109

ISSN: 0123-8418

ISSNe: $2215-7484$

Ciudades y conflictos en América Latina: ayer, hoy y mañana (I)

\title{
Espacio urbano, narrativas de desprecio y "limpieza social” en Bogotá
}

Urban Space, Narratives of Contempt and "Social Cleansing" in Bogotá

Espaço urbano, narrativas de desprezo e "limpeza social" em Bogotá

Ingrid Carolina Pabón Suárez ${ }^{*}$

Recibido: 19 de abril de 2016

Aprobado: 21 de octubre de 2016

Doi: http://dx.doi.org/10.12804/revistas.urosario.edu.co/territorios/a.4836

Para citar este artículo:

Pabón Suárez, I. C. (2017). Espacio urbano, narrativas de desprecio y "limpieza social” en Bogotá. Territorios (36), 87-109. Doi: http://dx.doi.org/10.12804/revistas.urosario.edu.co/territorios/a.4836

* Este artículo recoge parte de los resultados de mi tesis de maestria "Limpieza social” en Bogotá: la construcción de lo indeseable.

* Magister en Antropología de la Universidad Nacional de Colombia e integrante del Grupo de investigación Conflicto social y violencia, Centro de Estudios Sociales, Universidad Nacional de Colombia. Correo electrónico:icpabons@unal.edu. co. ORCID: http://orcid. org/0000-0001-5083-5274 
Palabras clave

Violencia urbana, narrativas, desprecio, limpieza social, Bogotá, Colombia.

Keywords

Violence, social cleansing, narratives, contempt, Bogotá, Colombia.

Palavras-chave

Violência urbana, narrativas, desprezo, limpeza social, Bogotá, Colômbia.

\section{tersitarias 36}

\section{RESUMEN}

"Limpieza social" es una categoría usada ampliamente para referirse a la acción de asesinar sujetos considerados indeseables. Quienes la ejercen esgrimen usualmente como argumento velar por la seguridad de un grupo social. Sugiero que esta práctica tiene un carácter instrumental, porque a través de ella se busca establecer un tipo de orden moral y social, expresivo, porque devela una estructura social jerarquizada y un sistema de clasificación que se soporta en la creencia de que hay unos sujetos que son fuente de peligro, los indeseables, y otros, que son quienes están en peligro. Como resultado de esta investigación etnográfica, cuyo escenario fue la Unidad de Planeamiento Zonal Patio Bonito, se concluye que esta acción violenta está mediada por construcciones discursivas que en este caso llamo narrativas de desprecio.

\section{ABSTRACT}

"Social cleansing" is a category widely used to refer to the act of killing people that are considered undesirable. Its perpetrators usually evoked it as an excuse to ensure the safety of a social group. I suggest that this practice becomes instrumental because it seeks to establish a particular kind of moral and social order; as well it is expressive because it reveals a hierarchical social structure and classification system that is supported by the belief that there are some individuals who are a source of danger, the most undesirable, and others, who are in danger. This ethnographic research, whose stage was the Zonal Planning Unit Patio Bonito, concludes that this violent action is mediated by discursive constructions in this case call narratives of contempt.

\section{RESUMO}

"Limpeza social" é uma categoria usada amplamente para se referir à ação de assassinar sujeitos considerados indesejáveis. Quem a exercem, esgrimem usualmente como argumento, velar pela segurança de um grupo social. Sugiro que esta prática tem um carácter instrumental porque através dela busca-se estabelecer um tipo de ordem moral e social. E expressivo, porque revela uma estrutura social hierarquizada e um sistema de classificação que se suporta na crença de que há uns sujeitos que são fonte de perigo, os indesejáveis, e outros, que são quem estão em perigo. Como resultado desta investigação etnográfica, cujo cenário foi a Unidade Planejamento Zonal Patio Bonito, se conclui que esta ação violenta está mediada por construções discursivas que neste caso chamo narrativas de desprezo. 


\section{Introducción}

Corría el año 2009 cuando se desarrolló el trabajo de campo para el proyecto de investigación "Violencia escolar en Bogotá: una mirada desde los maestros, las familias y los jóvenes. Aplicación de un modelo cualitativo de intervención y prevención de violencia en escuela, familia y barrio" 1 en cinco localidades de Bogotá. Uno de los objetivos fue explorar las relaciones entre la violencia escolar y otras expresiones de violencia a través de los testimonios de profesores, padres y madres de familia, líderes barriales y estudiantes de cinco instituciones educativas. Era un momento álgido en distintos barrios de la ciudad porque circulaban panfletos anunciando nuevas acciones de "limpieza social". En los relatos de los habitantes eran continuas las alusiones a esta situación. Fue precisamente el amplio uso de la categoría y la aceptación manifiesta de este tipo de práctica por parte de algunos residentes de distintos barrios lo que motivó la investigación que desarrollé entre el 2012 y el $2015^{2}$.

¿Por qué razón existe una amplia aceptación de un tipo de violencia reconocida ampliamente bajo la expresión "limpieza social"? ¿Cómo se construye la idea de un sujeto como no deseado? ¿Cuál es el soporte cultural de este tipo de violencia? ¿Cómo se vincula este tipo de violencia con los procesos de configuración de la ciudad? Estos interrogantes orientan el presente artículo que recoge parte de los resultados de la investigación ${ }^{3}$, cuyo escenario etno- gráfico fue la Unidad de Planeamiento Zonal - UPZ ${ }^{4}$ Patio Bonito.

El interés inicial fue explorar aquellas prácticas que dan soporte a esta acción violenta. Sin embargo, la observación de las dinámicas barriales y las relaciones de confianza que se tejieron a medida que avanzaba el trabajo de campo le dieron un giro a la investigación: hacer visible tanto las experiencias de los habitantes de los barrios expuestos continuamente a situaciones de inseguridad, un importante resorte de esta práctica, pero también, las experiencias de personas que ejercen la violencia y el delito en los barrios y que se vuelven focos de esta forma de violencia. Dar cuenta de las dos posturas devela la complejidad de este fenómeno social, considerado desde distintos sectores de la sociedad como parte del pasado. Esta investigación muestra, entre otras cosas, su vigencia.

Uno de los argumentos centrales es que las nociones de autoridad y de violencia juegan un papel insospechado en la aceptación de esta práctica. Pero además, que hay un potente mediador de esta acción violenta que denomino narrativas de desprecio. Estas son construcciones discursivas cuyo soporte son prejuicios, estereotipos y estigmas (entendidos desde Goffman, 1971), que abren el campo para el ejercicio de la violencia contra cierto tipo de sujetos. También sostengo que esta violencia hizo parte del proceso de configuración barrial, particularmente en escenarios donde la presencia institucional era muy precaria.
${ }^{1}$ Este proyecto fue coordinado por Bárbara García, profesora del Doctorado Interinstitucional en Educación de la Universidad Distrital Francisco José de Caldas y Javier Guerrero, profesor de la Universidad Pedagógica y Tecnológica de Colombia. Yo participé como asistente de investigación.

${ }^{2}$ En el informe del Centro de Memoria Histórica realizado por Carlos Mario Perea, titulado "Limpieza social" una violencia mal nombrada (2016) se propone llamar esta acción violenta como matanza social o exterminio social. Sin embargo, el uso de la categoría en mi artículo tiene como fin mostrar la manera como en Bogotá es nombrada un tipo de violencia.

${ }^{3}$ Con esta investigación obtuve el titulo de Magister en Antropología. Para profundizar, la tesis está publicada en el repositorio institucional de la Universidad Nacional de Colombia. Puede revisarse también el documento "Las narrativas de desprecio: el sujeto "ñero" y la "limpieza social” en Bogotá”. En M. Jimeno, C. Pabón, D. Varela e I, Díaz. (Eds.). Etnografías contemporáneas III: el uso de la narrativa en la investigación antropológica ( $p$. 217-237). $\Rightarrow$

territarias 36 
$\Leftarrow$

Bogotá: Centro de Estudios Sociales, Unipersidad Nacional de Colombia.

${ }^{4}$ Es un instrumento de planeación de la ciudad reglamentado a través del Decreto 469 de 2003. Consiste en una división administrativa de la ciudad, más pequeña que la localidad, pero que involucra un número variado de barrios que comparten características de infraestructura y equipamiento. La UPZ Patio Bonito fue reglamentada a través del Decreto 398 de 2004 de la Alcaldía Mayor de Bogotá.

${ }^{5}$ Mientrasparticipé en procesos de organización social en el 2006 se discutió en varias ocasiones la constitución de Patio Bonito como una nueva localidad. Una de las razones esgrimidas por habitantes de otras UPZ de la localidad de Kennedy, era el impacto de la acción delictiva ejercida en Patio Bonito sobre las cifras de delitos de la localidad.

${ }^{6}$ En julio del 2006 el periódico El Tiempo publicó una noticia bajo el titular "La zona más violenta de Bogotá". Aludía a distintos barrios de la localidad de Kennedy, particularmente de las UPZ Patio Bonito $y$ Corabastos. En el 2011, Caracol Radio calificó a la localidad de Kennedy como "una de las localidades más

territarios 36 90
El artículo está estructurado de la siguiente manera: hablaré en primer lugar de mis elecciones metodológicas, luego de los hallazgos y cerraré con unas consideraciones finales. En los hallazgos abordaré la razón por la cual esta práctica se vuelve parte del relato histórico de los barrios y daré cuenta de los sentidos que adquiere en un contexto local.

\section{Metodología}

El enfoque etnográfico, como lo ha planteado Jimeno \& Arias $(2000 ; 2011)$, es un ejercicio de ciudadanía. Las investigaciones antropológicas tanto en Colombia como en América Latina han mostrado el interés prioritario que otorgan los antropólogos al estudio de las situaciones sociales que tienen lugar en las sociedades de las que hacen parte. Ese es precisamente el punto de partida de esta investigación, la pregunta por un fenómeno social que está anclado a la historia de esta ciudad.

La etnografía también se constituye en una herramienta que permite tanto el acercamiento a las experiencias de vida de las personas, como el extrañamiento. En virtud de los lazos de confianza que se tejen, permite dar cuenta de los sentidos que tiene esta acción para los habitantes. Explicar y comprender la complejidad de las relaciones sociales en torno a esta práctica denominada "limpieza social", abre la posibilidad de pensar cómo puede ser abordada para evitarla, pues viola la integridad y la dignidad de los sujetos que se vuelven víctimas de ella.
Mi elección del escenario etnográfico se sustentó en tres criterios: el estigma que recae sobre esta zona ${ }^{5}$, pues históricamente Patio Bonito (al igual que otros lugares de la periferia bogotana) ha sido percibido como un espacio geográfico y social violento. En ello han jugado un papel protagónico los medios de comunicación y sus explicaciones simples de los acontecimientos de la ciudad ${ }^{6}$. Un segundo criterio fue la alta concentración de homicidios, específicamente de jóvenes y con arma de fuego entre el 2011 y el 2012 como lo muestra la figura 1. Para el 2011 la Policía Metropolitana de Bogotá registró un total de 49 homicidios con arma de fuego en esta UPZ, ocupando el segundo lugar después de Lucero. Y, en el 2012, registró 31 homicidios bajo esta modalidad, manteniéndose en el mismo puesto $^{7}$. Finalmente, el tercer criterio fue el relato histórico de los habitantes ligado a experiencias de violencia. Realicé varias temporadas de trabajo de campo entre el 2012 y el 2015 de fines de semana, una y dos semanas, pero la exploración etnográfica se concentró en el 2014 cuando habité en uno de sus barrios durante cuatro meses. Las fuentes etnográficas fueron los diarios de campo, los relatos de habitantes de los barrios (líderes barriales, cofundadores de los barrios, jóvenes y profesores), los panfletos que recolecté entre el 2009 y 2014 a través de prensa y redes sociales, las noticias sobre "limpieza social" publicadas en el periódico El Tiempo y El Espectador entre el 2012 y 2015 y algunos documentos institucionales que aludían a esta práctica. 
Figura 1: Concentración de homicidios de jóvenes (14-26 años) primer semestre 2011 y primer semestre 2012
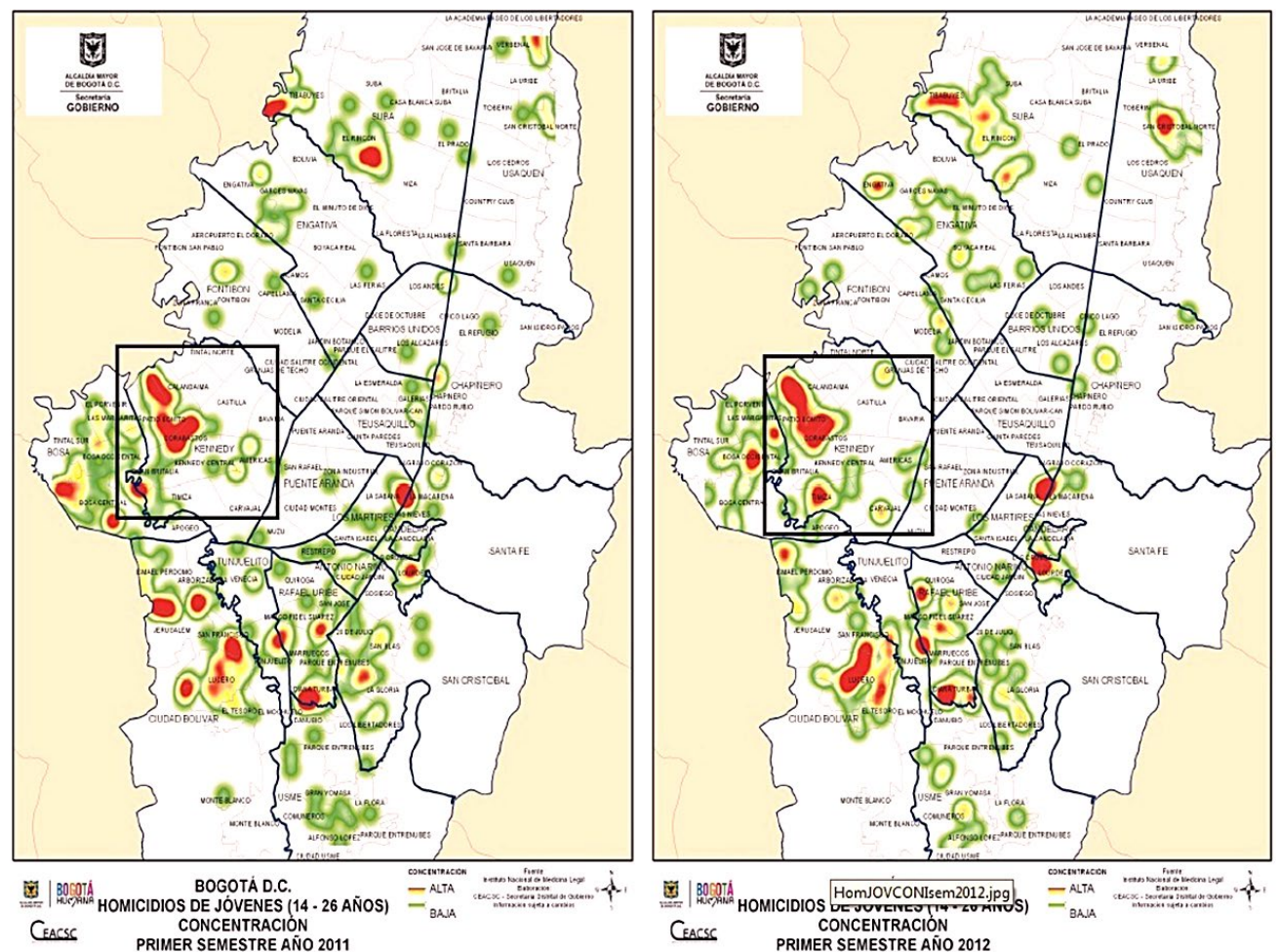

Fuente: Centro de Estudios y Análisis de Convivencia y Seguridad Ciudadana. (2012). La zona que aparece dentro del recuadro negro corresponde a Patio Bonito y Corabastos. Las manchas más oscuras representan una concentración alta de homicidio de jóvenes.

\section{Configuración barrial}

Patio Bonito es el nombre de los primeros tres barrios que emergen en esta zona periférica de la ciudad desde mediados de la década de 1970: Patio Bonito $1^{\text {er }}$ Sector, $2^{\text {do }}$ Sector y $3^{\text {er }}$ Sector. De acuerdo con Don Manuel, un reconocido líder barrial, el boom mediático que se desató con la inundación de este conjunto de barrios en 1979 hizo que este nombre se volviera emblemático y que abrigara el nombre de los otros 12 barrios ya conformados en ese entonces. Posteriormente, en el 2004, cuando se reglamentó este conjunto de barrios como UPZ adoptó el nombre de Patio Bonito, dando continuidad a la manera de reconocer este sector de la ciudad.

Estos barrios emergen en el marco de la expansión urbana acelerada que
$\Longleftarrow$

violentas de Bogotá". Mientras que, el 27 de febrero del 2014, RCN sostuvo que los cinco barrios "más peligrosos de la capital" estaban ubicados en las localidades de Rafael Uribe Uribe, Ciudad Bolivar, San Cristóbal y Usme, cuatro de ellas ubicadas en el borde capitalino. El 26 de enero de 2016, nuevamente el periódico El Tiempo señaló que las zonas que "ponen más de la mitad de las muertes en Bogotá" (Serrano, 2016) son Ciudad Bolivar, Kennedy, Usme, San Cristóbaly Rafael Uribe Uribe. El denominador común de estas noticias seleccionadas es que informan que en estos lugares se concentran distinto tipo de acciones delictivas $y$, por eso, se constituyen en las más violentas. Sin embargo, no hay un análisis de las razones por las cuáles el crimen se expresa con mayor intensidad alli. Asi, fácilmente el delito tiene su explicación, simplificada además, en la asociación entre lugares geográficos, condición socioeconómica y crimen. Abora bien, la prensa no es la unica fuente para sustentar esta afirmación. En la vida de los habitantes de Patio Bonito, la estigmatización se ha traducido en dificultades para lograr empleo, para tomar un servicio de taxi y para acceder a distintos servicios $\Longrightarrow$

\section{territarias 36}


$\Leftarrow$

de la ciudad. Situación que fue particularmente intensa en la década de los 90.

${ }^{7}$ Cifras tomadas de la base de datos de la Policía Metropolitana de Bogotá facilitada por la Secretaría de Gobierno en el 2015. En esta base de datos se registró un total de 68 homicidios para el año 2011 y 41 homicidios para el 2012 (CEACSC, 2015). Sin embargo, en un documento oficial facilitado por la Policia Metropolitana de Bogotá en ese mismo año, se registraron un total de 53 homicidios en el 2011 y 47 en el 2012. A pesar de las diferencias en las cifras de las dos fuentes consultadas, Patio Bonito aparece como la segunda UPZ de Bogotá con mayor número de homicidios registradosen estos dos años. Ahora bien, la ocurrencia de homicidios no significa la ocurrencia de casos de "limpieza social", por eso los relatos de los habitantes fueron contundentes.

${ }^{8}$ Para profundizar en la configuración del barrio bajo el protagonismo de sus habitantes, puede consultarse el trabajo El nacimiento y constitución del barrio Patio Bonito y la importancia de la junta de acción comunal en su desarrollo. Una mirada comunicacional (2005) de

territarias 36

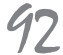

experimentaron durante el siglo XX Bogotá y otras ciudades latinoamericanas. Hubo principalmente dos razones: las migraciones masivas de población rural hacia las zonas urbanas y el crecimiento vegetativo de la población. Pero tanto la debilidad de las instituciones que vieron desbordada su capacidad para responder a la demanda de vivienda, así como la desigualdad y la pobreza (factores estructurales de la configuración de la ciudad) se reflejaron en construcciones barriales al borde del perímetro de la ciudad en condiciones precarias.

Este asentamiento urbano, como posiblemente otros en la ciudad de Bogotá, se caracterizó porque fueron los habitantes los protagonistas de su historia, particularmente en las primeras fases de poblamiento ${ }^{8}$. La autoconstrucción se convirtió en el mecanismo usado por excelencia para levantar las viviendas. Emprendieron luchas colectivas para lograr los servicios públicos y la mejora de sus condiciones de vida. Sin embargo, debieron habitar sus barrios en condiciones muy precarias por largo tiempo.

Otro aspecto que caracterizó a este conjunto de barrios fue la constitución de las viviendas como eje de la vida familiar y barrial, pues en torno a su construcción se congregó la comunidad y se tejieron lazos vecinales que permitieron la colaboración entre familias para alcanzar ese logro. La vivienda era un símbolo de progreso, una garantía para la vejez y para las generaciones venideras, así como la materialización de un sueño.
La tercera característica de Patio Bonito es su configuración como un microcosmos de movimiento poblacional porque el levantamiento paulatino de sus 44 barrios a lo largo de casi cinco décadas, mostró que había una continua llegada de población?. No en vano en la actualidad es una de las UPZ más densas de la ciudad, y un punto de concentración de población en situación de desplazamiento (Alta Consejería para los Derechos de las Víctimas, la Paz y la Reconciliación, s.f. $)^{10}$. Esto se asocia con los bajos costos de vida y la oferta: laboral, servicios educativos, de salud, comercio, entre otros. Por eso es usual encontrar habitantes cuya vida se teje solo allí: su trabajo, sus momentos de esparcimiento, la educación de sus hijos, los servicios de salud, el acceso a bienes y servicios que ofrecen las extensas redes de comercio. Además, porque una forma de poblamiento de esta zona fue la llegada paulatina de segmentos de la familia, como lo muestra el siguiente relato:

Alberto: Nosotros llegamos acá porque a mi mamá, mi abuelo le vendió un lote $[\ldots]$ antes pagábamos arriendo entonces andábamos de un barrio a otro (dentro de Patio Bonito). [...] luego del lote, construimos y desde ahí hemos vivido siempre acá. [...] y después mi abuelo le vende otro lote a otra tía y después varios familiares se vienen a vivir aquí, entonces se estabiliza la familia. El proyecto de vida se hace es acá en el barrio porque ya no solo está mi mamá sino que hay varias hermanas de mi mamá y con el matrimonio también. Entonces están

Ingrid Carolina Pabón SuÁrez 
mis primos. Ya éramos una familia grande, constituida dentro del barrio. Y pues ya salir del barrio con toda la familia digamos que es... aunque uno no lo quiera uno siempre está buscando como [al lado] de la familia (Entrevista Alberto, 2012).

Ahora bien, en los últimos quince años se desarrollaron nuevas fases de poblamiento en las zonas aledañas a esta UPZ. La estética limpia y homogénea de los conjuntos residenciales que acogen cientos de casas pequeñas construidas a modo de réplicas, apiladas tras rejas y muros, contrastan con las amplias viviendas de

Figura 2: Patio Bonito y Calandaima. Canal que divide los barrios de la UPZ Patio Bonito y las nuevas dinámicas de urbanización de la UPZ Calandaima a la izquierda

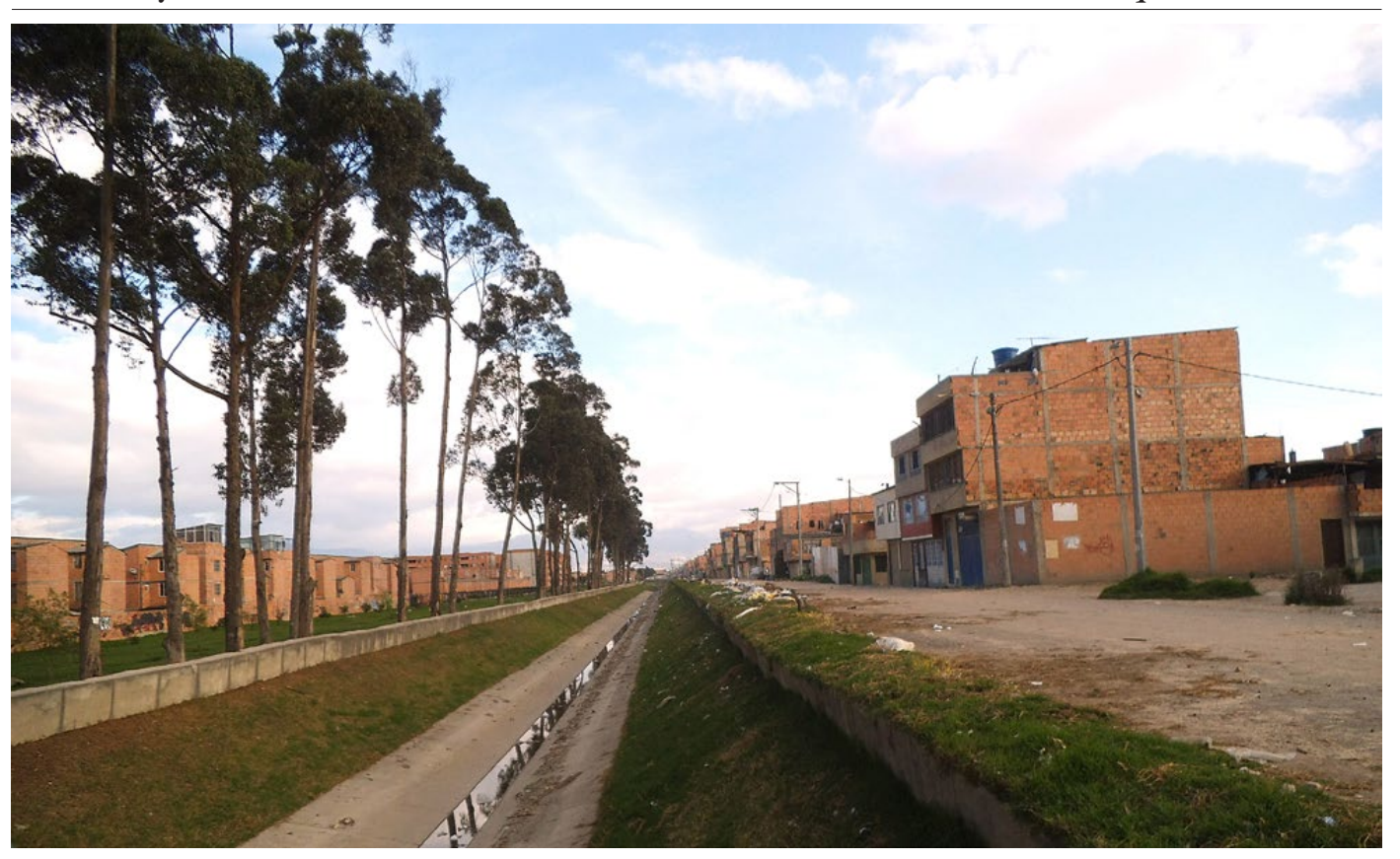

Fuente: Fotografía propia. (2013).

ESPACIO URbANO, NARRATIVAS DE DESPRECIO Y “LIMPIEZA SOCIAL” EN BOGOTÁ
Manuel Díaz, líder barrial de Patio Bonito.

9 Patio Bonito es la UPZ más densa de la localidad de Kennedy con 549 hab/ ha (Secretaria Distrital de Planeación, 2011).

${ }^{10}$ Para el 2013 se estimó que en la localidad de Kennedy habia un total de 20.598 victimas, siendo la tercera localidad receptora después de Ciudad Bolivar y Bosa. En Patio Bonito se concentra el mayor numero de personas victimas de desplazamiento con un porcentaje de $36.1 \%$ (Hospital del Sur, 2013; Alta Consejera para los Derechos de las Victimas, la Paz y la Reconciliación, s.f.).

territarias 36

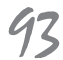


para el Estado durante los últimos dieciséis años, persisten en los barrios de esta UPZ las condiciones de pobreza y desigualdad, los mercados informales de vivienda, la concentración de acciones delictivas, pero además, el estigma sobre este conjunto de barrios. El interés por lograr dichas transformaciones que puedan responder a la demanda de vivienda no ha derivado en un proceso acelerado para que las condiciones de vida de todos los habitantes de esta UPZ sean dignas.

La historia de Patio Bonito es reveladora. Además de lo señalado anteriormente, muestra que la ciudad no ha estado al margen del conflicto nacional. Las experiencias de violencia de sus habitantes evidencian que los conflictos nacionales reverberan en lo local. La comercialización de drogas ilícitas, la presencia de actores armados y el crimen organizado permearon el relato histórico de este conjunto de barrios, particularmente desde la década de los 80. En Patio Bonito, estas situaciones se vinculan de manera particular con la cercanía a Corabastos, un lugar que ha estado signado por la presencia de actores armados y el desarrollo de actividades ilegales.

Sobre este proceso vivido en distintos sectores de la capital no se encuentra mucha bibliografía. Feltrán (2011) aborda este proceso para el caso de las periferias de São Paulo donde arribó una primera generación de habitantes que dieron lugar a la constitución de los barrios en la década de los 70. Una clase trabajadora que ha participado activamente de movimientos políticos. Sin embargo, dos décadas después se establece un marco discursivo alrededor del crimen que entra en disputa por la legitimidad, con los discursos en torno al trabajo, la familia y la iglesia, instancias que habían sido centrales para los primeros pobladores.

Esto que señala Feltrán es una pista para explorar lo que sucedió en el caso de las periferias bogotanas. En Patio Bonito, las condiciones precarias de vida se volvieron un caldo de cultivo para que los jóvenes se vincularan a la vida delictiva. Hay que decir de manera contundente que la pobreza no es determinante de la participación en el delito, pero sí es una situación que coadyuva a la configuración de un escenario de posibilidad para la vinculación de niños y jóvenes a un tipo de delito en el que se reproduce el lugar social marginal.

\section{Experiencias de violencia}

Para simplificar este aparte señalo cuatro aspectos a los cuales están asociadas las experiencias de violencia de los habitantes de Patio Bonito: la presencia de actores armados, la agresión ejercida por jóvenes que se vincularon de manera temprana a la vida delictiva, las acciones de venganza que se desataron entre distintos grupos (pandillas, grupos armados, crimen organizado) y la "limpieza social".

En relación con la presencia de actores armados, particularmente finalizando la década de los 90, el siguiente relato de un joven que vivió en Patio Bonito hasta el año 2011 es significativo: territarias 36 94 
Alex: Antes no había todas esas casas, todos esos apartamentos. Eso era totalmente un bosque completo, hermosísimo. [...] Se sentía mucho la naturaleza, el ambiente... pues pasar en la luz del día era muy bonito. En la noche no porque ya recorrían los caminos los paramilitares. Reclutaban pelados, les prometían muchas cosas como por ejemplo "usted trabaja con nosotros chino, un fierro [arma de fuego]... es andar por las calles. Usted va a ser un duro del parque". A mí una vez me lo prometieron y yo tenía solamente como 12 años. Me prometieron que me daban plata, que iban a ayudar a mi familia, y que trabajara para ellos. Tenía que cargar el arma, "vigilar el barrio" me decían, "usted tiene que vigilar el barrio porque es que por acá no se nos puede volver un nido de viciosos". Ellos cogían a cualquier pelado que veían en la esquina por ahí fumando yerba [marihuana], y los llevaban hasta el bosque y los castigaban, los amarraban (Entrevista a Alex, marzo de 2015).

Patio Bonito fue el escenario de una red enmarañada de actores que aplicaban cada uno sus propias reglas. Los habitantes de los barrios presenciaron de distintas maneras las conflictivas interrelaciones entre estos actores que se disputaron no solo el control del territorio alrededor del delito, sino sus perspectivas sobre las dinámicas de los barrios. Ejercieron sanciones morales sobre prácticas como el consumo de marihuana y de alcohol:

A mi papá le pegaron una vez. [...] Mi papá ese día guardó el carro y mira que no fue tan tarde [como] a las 9 de la noche porque le había ido bien. [...] Se emborrachó, enloqueció, bueno... empezó a caminar desde el paradero ${ }^{11}$ hacia arriba [oriente] y pasaron unos manes en caballo, porque ellos andaban en caballo o en las zorras. Los paramilitares nunca andaban en carro. Yo no sé qué fue lo que le dijeron a mi papá, y mi papá de pronto se puso de alebrestado [altanero] con los manes [hombres] o algo así. Lo cogieron y le dieron muy duro, muy duro [golpearon]. Tenía los dos ojos súper inflamados. Aparte le partieron una costilla y ahí si nos tocó corra pa'l medico con él. Pero no es muy claro.... o sea, no recuerda qué fue lo que le dijeron ellos, ni se acuerda qué fue lo que le respondió, sino que ya fue que se bajaron del caballo y le empezaron a dar [golpear]. Mi papá sí dijo "se me quitó la borrachera cuando el man me puso el cuchillo en el cuello". Empezó a decirles que él tenía hijos "mis hijas, mis niños" "ah ’̧tiene hijos y emborrachándose y volviéndose loco? No llegará loco a la casa" le dijo el man. Ese día llegó sano [calmado], vuelto nada pero sano, "a mí se me pasó la borrachera, se me pasmó". Pues como no, después de una muenda [golpiza] de esas y que te pongan un cuchillo acá, se le pasa todo lo que tenga. Esa fue una experiencia que nos tocó, que nos tocó a muchos de nosotros (Entrevista a Alex, marzo de 2015).

Lo que señala la narración es que había una comprensión por parte de los habitantes sobre la manera en la que se debía proceder frente a estas personas para evitar la agresión e incluso la muerte. La golpiza
${ }^{11}$ Lugar donde finalizan el trayecto los buses de servicio público. territarias 36

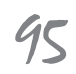


sufrida por su papá fue la consecuencia de no hacerlo. Alex, quien ahora tiene 29 años, cuenta que en ese momento los barrios ubicados al occidente del actual Parque Bellavista eran de invasión y que fue allí donde se concentraron muchas acciones violentas que marcaron la historia de vida de los residentes.

Por otra parte, un joven que vivió parte de su infancia en Pinar del Río - uno de los barrios aledaños a Corabastos - a unas cuantas calles de lo que es hoy la UPZ Patio Bonito, señala lo siguiente:

Yo me acuerdo que cuando estaba esa gente del M-19 había más control de muchas cosas. O sea, no había tanto hurto, no se veía tanto de eso. Yo no sé si ellos se dedicaban a ese tipo de actividades, a lo de "limpieza social" y esas cosas. Yo no sé qué hacían (Entrevista a Vicente, julio de 2013).

Muchos barrios de la ciudad se configuraron ligados al ejercicio de distintas formas de violencia. La violencia, ejercida por distintos actores - entre ellos los habitantes-, se volvió un mecanismo de respuesta allí donde la institucionalidad parecía ausente. Modeló formas de habitar el barrio pues, a raíz de las acciones de estos agentes, los habitantes desarrollaron estrategias para su seguridad, como no permanecer en la calle a determinadas horas, no caminar solos, evitar relacionarse con desconocidos. Pero también la presencia de diversos actores armados configuró un escenario de impunidad, pues se ejercieron acciones en nombre de ellos y en contra de los jóvenes que se volvieron no deseados por sus formas de habitar el barrio.

\section{Los efectos de la acción delictiva juvenil}

Edilberto ha construido toda su vida entre estos barrios. Sin embargo, a pesar de su vínculo emocional con este territorio citadino, debió enfrentar en distintas etapas de su vida experiencias desafortunadas con los jóvenes implicados en delitos. La siguiente fue una de sus tantas experiencias:

Yo venía por la acera derecha y venían cuatro ñeritos hacia acá, entonces yo, ¡mierda! [...] el tipo me dijo que "quieto, una requisa" Yo me hice el güevón y seguí caminando. El tipo me hizo así con la macheta pero [...] esa vaina rebotó [contra un cinturón que llevaba puesto]. Obviamente me robaron [...]. Tenía cinco mil pesos en el bolsillo de atrás y tenía un reloj que pues yo quería harto. Lo que más me ofendió es que cogieron mi billetera y empezaron a botar los papeles así y me dieron la billetera, y bueno, listo, uno la recoge ¡pero lárguense! Ahí parados viendo como yo recogía los papeles. Me sentí tan humillado que ni siquiera fui a trabajar. Imagínate lo que hice. Me devolví y saqué la escopeta de la casa y la metí en un trapo que tenía ahí. Me puse a buscarlos [... [pero] me arrepentí y me tocó morderme la rabia y devolverme pa' la casa (Entrevista a Edilberto, octubre de 2013).

A partir de este relato es posible subrayar dos cosas. La primera de estas, los 
efectos que generan este tipo de experiencias: la producción de miedo y desconfianza, la impotencia y la ira y el odio hacia estos jóvenes, particularmente en los casos en los que hubo humillación; estos efectos se asocian con la posibilidad de la respuesta violenta frente a la agresión. La segunda es la emergencia en los relatos de la categoría de "ñero" para referirse a los jóvenes que ejercen acciones delictivas, en este caso usada de manera peyorativa:

El punto es que si tú matas un ñero, vienen, miran, entierran y se quedan. La cuestión de las camadas. Que le mataron el papá ñero, pues sencillamente él sabe que creció con ese rencor o sencillamente escuchó hablar a la familia "que vamos a vengarnos". Así creció, se volvió ñero, se fue formando y viene la otra camada (Entrevista a Edilberto, octubre de 2013).

Este símil que establece Edilberto entre los sujetos involucrados en el delito - particularmente el robo y el atraco-y las especies animales que tienen varias crías tan solo en un parto, muestra el juego de la relación entre representación y humanización señalado por Butler (2010): el reconocimiento de la calidad humana de una persona está vinculado directamente a la manera como es representado. Lo que es evidente en este caso es que la acción discursiva en torno al sujeto se desplaza de sancionar su acción a emplazarlo en el campo de lo no humano (Foucault, 2001), porque infringe con violencia unos principios de convivencia y el detonante principal es el sentimiento de humillación. Ahora bien, esto manifiesta de alguna manera cómo se aprehenden esas vidas y las formas de aprehensión de la vida se vincula con el reconocimiento de cuáles vidas deben ser guardadas de la violencia y cuáles no (Butler, 2010). Pero quiero decir que esto es dialógico. Es decir, no es solo cómo los residentes aprehenden la vida de quiénes se vinculan al delito, sino cómo quienes se vinculan al delito aprehenden la vida de los residentes. En este caso, las narrativas construidas en torno a los sujetos que delinquen son una respuesta a la rabia y a la desazón experimentada tras la acción delictiva y la humillación.

Hay que decir también que la categoría "ñero" es usada por algunos jóvenes del sector como una categoría de autoidentificación. Al respecto dice Alberto, un hombre que vive en estos barrios:

Uno decía un ñero es una persona de bajos recursos, con muchas necesidades y que creció dentro de una realidad. [...] Hay chinos que quieren aparentar ser ñeros como para tener aunque sea ese respeto y tratan de vestirse ñero y uno va y viven en un buen apartamento y uno dice pero por qué son ñeros y yo no sé si es que se vuelve moda. [...] Acá en Patio Bonito uno iba allá abajo y veía ñeros porque habían zorreros y todo eso, porque surgieron dentro de todo eso [...] Pero últimamente... se volvió fue moda. Ya un ñero no era un ñero por su situación social sino por moda o algo así. [...] Me acordaba cuando yo estaba así de chino. Yo pensé que esa moda ya no volvía cuando otra territarias 36 
vez vi todo eso, igualito. Las pantalonetas así de baloncesto, pero todo de los equipos de Estados Unidos de béisbol, de baloncesto, de fútbol americano. Eso era lo que antes se usaba. No sé, el sueño americano acá (risas) (Entrevista a Alberto, marzo de 2013).

De acuerdo con Alberto, en el momento en que se reconoció bajo dicha categoría, lo "ñero" estaba asociado a una condición social marginal. La configuración estética, inspirada en tendencias deportivas norteamericanas, se juzga como despreciable desde distintas esferas sociales, pero tiene una intención ya señalada: lograr respeto mediante el temor. Cuando Alberto siente que la tendencia se expande y no siempre se asocia a la experiencia de la pobreza y la marginalidad, lo interpela la necesidad que existe detrás del interés por lograr esta "fachada". Supone que dicho interés tiene que ver con los efectos de dicha estética. En ese sentido, la experiencia de lo "ñero" resulta relacional porque quién encarna el personaje sabe de antemano sus efectos en la producción de temor, porque se lo vincula con la acción delictiva y violenta. En términos estéticos, se sabe que no responde a los códigos y convenciones dominantes sobre lo agradable o lo bello. No solo está el consumo de objetos de manera particular, sino los gestos corporales y el lenguaje; así, el cuerpo se convierte en el mensaje. Del otro lado, del receptor, lo "ñero" es la condición estética que porta quien ejerce el delito, y el que se revista de algún gesto "ñero" se le acusa territarias 36 98
Ahora, así como se expande el deseo de encarnar "lo ñero", se expande el uso peyorativo de la categoría siendo atribuida a cualquier sujeto indeseable cuya condición social está signada por la pobreza. Además, lo "ñero" tiene una condición adicional: la violencia que ejercen algunos jóvenes reconocidos bajo dicha categoría los hace a su vez focos del ejercicio de la violencia llamada "limpieza social".

Volviendo a los efectos del hurto y el atraco, me interesa resaltar tres efectos en particular. El primero es que se convierten en resortes del "habla del crimen", una categoría con la cual Caldeira (2007) alude a las construcciones discursivas que se tejen en torno al crimen. Estas reproducen la sensación de miedo y desconfianza incluso entre quienes no han sido víctimas directas de acciones delictivas. El segundo es la producción de un repertorio de acciones de defensa que van desde la ruptura de vínculos sociales, cambios en la relación con el territorio, por ejemplo restricciones en la movilidad, hasta el impulso de mecanismos de justicia propia como la "limpieza social”. El tercero, y último, es la construcción de mediaciones discursivas que se soportan en mecanismos clasificatorios que trazan fronteras entre estos jóvenes y los demás habitantes a través de categorías binarias que se relacionan por oposición: buenos/malos, correctos/incorrectos, sanos/dañados y es en el campo del mal, de lo incorrecto y lo dañado que se ubica al sujeto "ñero". De esa manera se construye una representación particular del sujeto que ejerce la acción delictiva: le son impu- 
tados atributos que lo descalifican. Estas construcciones discursivas estructuran lo que llamo narrativas de desprecio ${ }^{12}$.

Por otro lado, están los esquemas de interpretación de las acciones de estos jóvenes. Es decir, la base cultural para aprehender e interpretar dichas experiencias. Dice Douglas (1973) que las experiencias cotidianas y las personas que participan de ellas son acomodadas a nuestra estructura de supuestos. En ese sentido encontré que hay dos nociones que son claves en la manera como se explica la acción delictiva y de violencia de estos jóvenes. La perspectiva de la violencia es una de ellas. Esta se comprende como "manifestación destructiva de la agresividad humana, suele considerarse encarnación del mal [...] Suele verse como furia de fuerzas descontroladas, irracionales, o es reducida a sus actores más extremos, lo que no permite contextualizarla" (Douglas, 2011, p. 8; Jimeno, Roldán, Ospina, Jaramillo, Calvo \& Chaparro, 1998). En ese sentido el sujeto es la encarnación del mal. El problema no es la acción del sujeto, sino el sujeto en sí mismo (Foucault, 2001). La segunda noción es la de autoridad, que se liga a la violencia. Para los habitantes la acción juvenil violenta se deriva de la falta de autoridad, pero una autoridad restrictiva y represiva que no ejerce la familia, la escuela y la policía. En esa medida hay una aceptación del control que realiza la fuerza pública de manera legítima sobre estos jóvenes, pero a su vez del ejercicio de una autoridad arbitraria que usa la violencia para controlar:
Ahora hay una Policía muy buena. De hecho llegó un sargento. Yo lo empecé a interpretar como una persona violadora de los Derechos Humanos porque es bastante atrevido con la gente. Les da duro mucho a las personas mal llamados “ñeros". Lo hace públicamente. Yo me imagino cómo será en otras partes... pero de una manera u otra ha sido mejoría de la seguridad para este sector (Entrevista a Ernesto, marzo de 2013).

El sujeto que encarna el mal y sobre el cual no se ha ejercido este tipo de autoridad es el sujeto incorregible. Cuando este se vuelve víctima de prácticas violentas como la "limpieza social", su muerte se comprende como consecuencia de su condición maligna y de su acción delictiva.

\section{Los jóvenes y el delito}

La otra cara de la moneda son los jóvenes que se vinculan al delito. Para registrarlo tomé como eje la trayectoria de vida de un joven que me permitió condensar la historia de otros jóvenes del sector. Él empezó a realizar tareas de apoyo al delito cuando apenas tenía once años, sin ser consciente de ello:

Él comenzó así conmigo [un joven de diecinueve años] "venga chino, venga" y yo era todo gordito, y todo chiquitico. "Qué papi, ¿qué necesita?”, “tome, le regalo quinientos". Cuando ya un día me dijo que si le iba a hacer un favor, y yo ya le debía favores porque él ya me había dado cosas, ya me había regalado moneditas, y yo le dije,
12 Zambrano (2014) coincide en señalar el desprecio como resultado de un "imaginario social" y como resorte de prácticas violentas como la "limpieza social" en contra de un grupo poblacional que es su foco de interés: los "gamines", particularmente en las décadas de los 80 y 90 en Colombia.

territarias 36

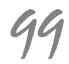


"claro". "Lléveme este bolso hasta Mitad de precio" y yo se lo llevé desde el otro parque de allá. Llegué a Mitad de precio, él cogió el bolso y cogió una puñada de monedas y me las puso así en la mano. Y me dijo "nos vemos más tarde" y se fue con su bolso y yo me fui con mis monedas contento, con un poco de monedas pa' jugar maquinita, pa' llevar pa' la casa. A mí me gustaba mucho llevarle cosas a mi mamá. Comprar cosas y decir que me las habían regalado [suspira]. Entonces ya así comenzó, comencé yo a crecer al lado de ese muchacho (Entrevista a Camilo, marzo de 2013).

Tiempo después supo que el contenido del bolso eran armas. La participación de los niños en este tipo de tareas tiene como fin evadir los controles policiales que recaen sobre estos jóvenes. Cuando se mantienen en medio de estas redes por largo tiempo, construyen lazos afectivos con sus pares, partícipes también en tareas del delito. En ocasiones, sus "parceros" se convierten en una extensión de la familia o en la familia en sí misma. Es así que incurren en acciones cada vez más graves. De ejercer tareas como la descrita se involucran en delitos, atracos y en actividades asociadas a la comercialización de drogas. $\mathrm{Y}$, a medida que se escala en el delito, se vuelve más difícil desvincularse de las redes en las cuales se rodean de amigos, pero también de enemigos. Se trata de la construcción de fronteras físicas y simbólicas que trazan respecto a otros grupos, defendidas a través de la confrontación violenta, lo que les permite configurar un tipo de identidad ligada a los barrios.

Tanto las fronteras y las acciones asociadas a su defensa, como los riesgos propios de la acción delictiva, hacen que sus vidas tengan una continua proximidad con la muerte. De acuerdo con Butler (2010), la capacidad para aprehender una vida "es parcialmente dependiente de que esa vida sea producida según unas normas que la caracterizan, precisamente, como vida, o más bien como parte de la vida" (p. 16). Lo paradójico, en el caso de estos jóvenes, es que sus vidas resultan visibles para la comunidad barrial (en ocasiones para los medios de comunicación) por incurrir en el delito, pero no por las condiciones de pobreza que estructuran sus experiencias en la ciudad. Tanto la ineficacia del Estado para cumplir sus deberes en relación con la garantía de derechos de la población joven de Bogotá, como la percepción de los jóvenes sobre la vida de quiénes son víctimas de sus agresiones y la de ellos mismos, siempre puesta en riesgo, dibujan un panorama social en el cual la vida en sí misma tiene muy poco valor. El artículo 13 de la Constitución Política de Colombia consagra que "todas las personas nacen libres e iguales ante la ley, recibirán la misma protección y trato de las autoridades y gozarán de los mismos derechos, libertades y oportunidades sin ninguna discriminación...". Sin embargo, esto no ha sido suficiente para que "la violencia sea menos posible, las vidas más equitativamente dignas de duelo y, en general, más merecedoras de vivirse" (Butler, 2010, p. 25 ). Esto aboca al problema ético 
señalado por Butler (2010) "saber qué hay que reconocer, o, más bien, qué hay que guardar contra la lesión y la violencia”. Es entonces un asunto de cómo se configuran los mecanismos para clasificar las vidas y hacer que unas merezcan reconocimiento y otras no.

Pero ¿̨cuál es la base cultural que sustenta la experiencia del joven del barrio popular que usa la violencia como mecanismo de habitación del barrio? Para abordarlo quiero traer a colación este fragmento:

Carolina: ¿̨or qué ese camino y no otro?

Camilo: Porque no me dieron otra opción. [...] Era difícil, pero éramos alguien en la sociedad.

\section{Carolina: ¿̨Porque les tenían miedo?}

Camilo: Porque nos tenían miedo y nos respetaba todo el mundo. Es que ¿es muy fácil que uno llegue a un lado y lo respeten a uno? No es muy fácil. Y ¿cómo se gana el respeto? Con mucha educación ¿sí o no? Y si no la tiene ¿cómo se gana el respeto? Con mucha fuerza. Y si usted no tiene la educación pero tiene la fuerza y tiene las armas pa' que lo respeten, pues usted se hace respetar donde sea ¿no cree? [...] Siempre ha sido como el respeto ante todo (Entrevista a Camilo, marzo de 2014).

Mediante el ejercicio del delito y del uso de la violencia como mecanismo de habitación del barrio, estos jóvenes logran un poder sustentado en el ejercicio de la violencia. Ese poder tiene como soporte la noción de respeto y la noción de masculinidad. Con relación a la noción de respeto, este tiene un significado ambivalente señalado por Jimeno et al.: "significa simultáneamente amor y temor" y, además, inhibe la rebelión (1996). Pero la capacidad para retraer la acción del otro, por ejemplo en una situación de robo, puede responder al temor, no al respeto. Vincular el temor con el respeto legitima las prácticas violentas porque ser temidos significa ser respetados. En ese sentido el temor de las personas a la acción violenta de estos jóvenes se considera respeto. Pero, una vez vencido el temor por parte de algunos sectores de la sociedad, es arrebatada la vida de estos jóvenes a través de acciones como la "limpieza social".

Con relación con la noción de masculinidad, esta se ancla a la construcción de la imagen del "duro" y del "malo". Estas figuras aluden a un sujeto al cual el miedo no le impide actuar. Puede radicalizar la acción violenta hasta incluso la muerte propia o la del sujeto agredido; es una figura ambivalente pues administra violencia pero también puede convertirse en un mediador de los conflictos al interior de su grupo o más allá de él y, finalmente, pone de manifiesto la dimensión de género de la violencia urbana, es decir, muestra cómo la masculinidad se vincula de manera directa con la fuerza, el dominio, la agresión y la violencia (Auyero \& Berti, 2013). 


\section{"Limpieza social"}

Son los jóvenes que se vuelven visibles en la cotidianidad del barrio por sus acciones delictivas quienes se convierten en focos de este tipo de violencia:

A mi mamá le llevaron la boleta [panfleto] una vez. Allá aparecía yo. Yo tenía unos 17 años. Allá le llevaron la boleta. "Señora, si no saca a su hijo, se lo vamos a mandar en una pijama de madera". Me mandaron pal' pueblo otra vez. Mi mamá llorando un día, que me fuera. [...] Yo llegué ese día de la calle, no sé qué horas serían. Ella me dijo: "yo quiero que usted se vaya de la casa. Váyase de la casa porque aquí vino una gente, me mostró unas fotos y a usted lo tienen en la lista para matarlo" (Entrevista a Camilo, marzo de 2013).

La "limpieza social" es un tipo de acción violenta que incluye un repertorio de prácticas violentas: la amenaza, el desplazamiento, la tortura y el homicidio. Es una práctica selectiva y discontinua, usada para infundir terror en la población. Presenta rasgos particulares dependiendo de la zona donde se ejerza. Históricamente sus víctimas han sido habitantes de calle, identidades no hetero-normativas, mujeres que ejercen la prostitución y personas que delinquen (Camacho \& Guzmán, 1990; Rojas, 1996; Stannow, 1996; Pinzón, 2007). En Patio Bonito han sido víctimas los jóvenes identificados como "ñeros".

Las señales de alarma han sido la circulación de vehículos entrada la noche en los barrios, que dejan una estela de muerte a su paso, los homicidios de identidades usualmente amenazadas que impulsan el rumor de una nueva acción de "limpieza" los mensajes en los cuerpos, a veces torturados, una práctica muy común en las décadas de los 80 y 90 y principalmente los panfletos, escritos cortos, agresivos e intimidantes puestos en muros y postes, arrojados por debajo de las puertas de las casas, repartidos entre los habitantes de un sector, lo que se conoce como "panfletear”. En ellos se consigna la amenaza a personas de los barrios usando sus apodos, sus nombres o etiquetas sociales como marihuanero, vago, entre otras, lo que se conoce como "lista negra".

Los panfletos pueden ser anónimos o adjudicados a grupos armados como las Autodefensas Unidas de Colombia (AUC), bandas criminales o agrupaciones que se adjudican la labor de buscar la seguridad. Es usual que quienes hablan a través del panfleto se refieran a sí mismos como "gente de bien" que, ante las circunstancias, se ven obligados a recurrir al crimen para resolver la situación de inseguridad. Es conocida la participación de miembros de instituciones del Estado (Camacho et al., 1990; Rojas, 1996; Stannow, 1996; Ordoñez, 1995), de miembros de las Juntas de Acción Comunal y de los habitantes de los barrios (Perea, 2015).

Entre los argumentos que se esgrimen está la defensa de la "buena moral", la ineficacia de las instituciones (es así que los perpetradores se adjudican la misión de hacer lo que las instituciones de seguridad 
no logran), el carácter peligroso del sujeto "dañado" y, en conexión con este, el estado en que se encuentra la sociedad, calificada de "podrida". Ante el señalamiento de los sujetos como representación de lo dañado y de lo sucio, la solución entonces es "limpiar", es decir, asesinar a quienes se consideran la suciedad.

Entre tanto, en las noticias de prensa que dan cuenta de este acción violenta se suele reproducir el mensaje de los panfletos por fragmentos o, simplemente, se usa el panfleto para anunciar lo que está sucediendo. Lo que se logra es reproducir las categorías, los argumentos y las amenazas del panfleto sin dar luces sobre la comprensión de la situación ${ }^{13}$.

Además, se privilegia el discurso policial a través del cual se conceden explicaciones simples y aceleradas de los crímenes, por ejemplo, que están asociados con los contextos de las víctimas o con las prácticas en las que incurren. La mayoría de las hipótesis sobre los hechos, se ligan a la representación ya construida del sujeto-víctima: si consume drogas, las amenazas pueden venir de una comunidad incómoda por sus prácticas; si tiene antecedentes por incurrir en acciones delictivas, posiblemente sea ajuste de cuentas o producto de las riñas entre pandillas o bandas; si se presume que es expendedor o consumidor, las muertes se atribuyen a las disputas entre facciones del tráfico de drogas ilícitas en los barrios. Las hipótesis parecen solucionar en sí mismas el asunto de los homicidios. Su pretensión parece ser contrarrestar cualquier hipótesis asociada a la llamada "limpieza", no precisamente de aclarar lo sucedido. Si la persona asesinada es habitante de calle, se afirma que es usual que entre este tipo de identidades se asesinen. $O$ si es un joven que consume sustancias ilícitas, se asocia con las dinámicas de comercialización de drogas o con "ajuste de cuentas". Así, se constituye en un discurso con presunciones de verdad y efectos de poder, pues poseen valores demostrativos independiente de su estructura racional (Foucault, 2001).

Asimismo el uso de la categoría se reproduce en los documentos institucionales, en ocasiones sin ningún tipo de objeción al respecto, aunque se use entre comillas. También se reproduce el aura de misterio en torno a los perpetradores. Esto resulta paradójico porque es responsabilidad de las instituciones dar claridad sobre la situación. De modo que no se logran avances en la comprensión de este fenómeno que lleva varias décadas de vigencia y, de paso, pocos crímenes de este talante logran procesos judiciales exitosos.

Analizando este fenómeno desde la perspectiva de Douglas (1973) es posible afirmar que es una acción violenta de carácter instrumental con la que se busca defender un tipo de orden moral, vengar las afrentas a dicho orden y castigar las acciones reprobadas. También tiene un carácter expresivo porque, a través de su ejercicio, se muestra la manera como está configurada la red de relaciones en una estructura social. En relación con el nivel instrumental, la imposición del orden atraviesa dos etapas. La primera es el rechazo de sectores de la propia sociedad
${ }^{13}$ Un análisis de la prensa sobre este fenómeno lo realizó María Rocha (2009). El periodo de análisis fueron los años comprendidos entre 1988 y 1996. Un punto de confluencia con Rocha (2009) es el poder de los medios informativos para representar a la victima como un sujeto que se bace acreedor de un tipo de violencia por incurrir en determinadas prácticas. tersitarios 36

103 
porque son vistos como una amenaza. En esa etapa son fundamentales las narrativas de desprecio a través de las cuales se reproducen prejuicios, estereotipos y estigmas sobre ciertos sujetos. El peligro se vincula con identidades sociales específicas, a veces imputadas, a veces auto-reconocidas, como lo mostré en el caso de los jóvenes de barrios populares identificados como “ñeros". La segunda etapa es cuando esas identidades se desvanecen al entrar al conjunto de lo que significa "suciedad". Ser parte de ese conjunto es una sentencia de muerte cuando se ponen en marcha los grupos de exterminio.

En el nivel expresivo, hay que decir que la atribución de suciedad y de peligrosidad a sectores de la sociedad revela un mecanismo de clasificación que diferencia entre quiénes están en peligro y quiénes ponen en peligro a la sociedad, además, puestos de manera jerárquica en la escala de valor social de las vidas. Así, las vidas de quienes ponen en peligro son menos valiosas que aquellas que se consideran que están en peligro.

\section{Consideraciones finales}

En el 2006, en una noticia del periódico El Tiempo se calificó como la zona más violenta de Bogotá a un conjunto de cinco barrios distribuidos entre las UPZ Corabastos y Patio Bonito. El argumento fue el número de homicidios reportado, cuyo valor excedió el índice de otras localidades. Es así que fue nombrada por la policía como una zona crítica. Afirma el reportero que allí "residen unas 150 mil personas, miles de ellas desterradas por culpa de la violencia", lo que evoca la capacidad extraordinaria de quien escribe la noticia para dar cuenta de la situación por la que llegaron los miles de habitantes a los que alude.

A ello se suman unos niveles de pobreza escalofriantes, según lo constató $E l$ Tiempo en un recorrido por la zona. En cada esquina se ven a decenas de niños sin camisa jugando fútbol o simplemente con la arena y cantinas donde la gente se emborracha con totumas de guarapo que se venden a 1000 pesos. No es por "paras", ni guerrilla. La causa principal de los crímenes en esta zona no radica en el conflicto armado. "Detrás de la mayoría de las muertes - explica el coronel Pedroza- está la presencia del alcohol como generador de violencia intrafamiliar. En segundo lugar aparecen los crímenes por riñas callejeras, después de las venganzas entre bandas delincuenciales y los homicidios por ajustes de cuentas entre "zorreros" y recicladores" (El Tiempo, 2006).

La periferia como un lugar de pobres, desplazados, vías destapadas, donde la gente se emborracha con guarapo y los niños juegan sin camisa, apunta a establecer una relación entre el ejercicio de formas de violencia como el homicidio y las formas de vida de los residentes de estos barrios. De esta manera se construye una representación de los barrios y las localidades a partir de explicaciones simplificadas de la violencia. La estrategia, intencionada o no, es omitir el fondo histórico que ha dado 
lugar a la configuración de unos barrios donde, en efecto, se concentran distintos tipos de delitos. Es así que los medios de comunicación aportan a la construcción del estigma pero poco a la comprensión de por qué estos lugares se vuelven un locus del crimen.

Las formas de narrar la vida social de las periferias, por ejemplo en la prensa, ejemplifican lo que constituye una forma indeseable de habitar la ciudad por medio de los barrios a los que aluden. Las periferias, sus familias, sus jóvenes, sus niños, han sido convertidas en los problemas de la ciudad. Durante el siglo XX los barrios pobres fueron considerados como un obstáculo del ideal modernizador y civilizatorio hacia donde se direccionaron las propuestas higienistas, soportadas en la relación entre higiene y moral (Pedraza, 2001). Posteriormente, se les imprimió como característica la peligrosidad. Estos lugares se perciben como focos desde los cuales se propaga la delincuencia y otro tipo de prácticas asociadas con la inmoralidad. De esa manera, lo indeseable se espacializó.

Ahora, ese estigma que recae sobre sectores de la ciudad, se entreteje con las narrativas que se construyen en torno a los sujetos indeseables. Pero ¿qué es lo que hace a un sujeto indeseable?

Hay tres aspectos que convergen para que un sujeto sea percibido como una fuente de peligro. El primer aspecto es la condición juvenil que constituye un estado de transición, siendo un lugar de tensión e incertidumbre (Diógenes, 2011). Van
Gennep consideró que los peligros residen en los estados de transición, como lo destaca Douglas, "sencillamente porque la transición no es un estado ni el otro, es indefinible. La persona que ha de pasar de uno a otro está ella misma en peligro y emana peligro para los demás" (1973, p. 131). Pero no todos los jóvenes se perciben de tal manera. La proyección estética de los jóvenes aparece como un filtro más, un criterio de clasificación social que se ancla al capital económico y cultural y que constituye el segundo aspecto, lo que se refleja a través del uso peyorativo de la categoría "ñero" para señalar a ciertos sujetos bajo criterios estéticos. Con esta categoría se reconoce tanto a los jóvenes que habitan sus barrios haciendo uso de la violencia como a jóvenes que no se alinean con esas formas de vivencia barrial. Ambos comparten tres características: su pertenencia al barrio popular, un escaso poder adquisitivo y una estética y estilo de vida.

Entonces, el despliegue de violencia al interior de los barrios contra jóvenes de su misma condición social y económica y en contra de otros residentes es solo un aspecto de la indeseabilidad de los jóvenes. Este aspecto se superpone con atributos estéticos y morales que se les asignan a estos jóvenes pues no existe una relación determinante entre desear la estética juzgada de "ñera" y ejercer el delito y la violencia. Por otra parte, quienes tengan el infortunio de coincidir con estos atributos estéticos y morales, que usualmente se ajustan con la condición de ser joven y ser pobre y en ocasiones con criterios territarias 36

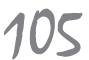


${ }^{14}$ Para un análisis de las representaciones construidas sobre otra identidad social, los niños de la calle, y su papel en el ejercicio de este tipo de violencia puede revisarse el trabajo de Zambrano es Marchi (2014).

tersitarias 36 106 raciales, experimentan las consecuencias de la segregación y la exclusión porque se consideran potenciales delincuentes. De manera que si una persona coincide en su forma de presentación personal con alguien que cometió una acción delictiva, será el centro de las reacciones de desconfianza en distintos escenarios de la ciudad. ¿Por qué? Porque cumple con la estética de un ladrón.

Esos sujetos considerados como indeseables son rechazados por los sectores de la sociedad que los ven como fuente de peligro y de amenaza. Para quienes ejercen y apoyan la "limpieza social" simplemente representan la suciedad. En ese sentido, la vida de quiénes son un peligro para la sociedad tiene menos valor que la de aquellos que deben protegerse ${ }^{14}$.

Allí radica el poder de las narrativas de desprecio, pues estas son mediaciones discursivas que abren la posibilidad para el ejercicio de la violencia a través de acciones como la "limpieza social". Son construcciones discursivas a través de las cuales se reproducen prejuicios, estereotipos y estigmas sobre ciertos sujetos, soportadas en mecanismos clasificatorios. A través de ellas se pone de presente "los esquemas normativos de inteligibilidad que establecen lo que va ser y no va a ser humano, lo que es una vida vivible y una muerte lamentable" (Butler \& Rodríguez, 2006, p. 182)

El ejercicio de ésta acción y la impunidad de los crímenes es el reflejo de un Estado que hace presencia de forma diferenciada en la ciudad, es decir, la ac- ción institucional resulta particularmente precaria en algunos sectores, lo que se convierte en un factor clave para entender el poder que logran por un lado las dinámicas del crimen y el delito y, por el otro, la precariedad de las condiciones de vida de muchos habitantes, así como la vigencia de prácticas como la "limpieza social" bajo el argumento de la seguridad. En el sustrato de esta práctica - como de otras formas de violencia (Jimeno, 1996) - están las nociones de violencia y de autoridad ya descritas.

\section{Referencias}

Alta Consejería para los Derechos de las Víctimas, la Paz y la Reconciliación. (s.f.). Comunicados de prensa. Recuperado de http://www.victimasbogota.gov.co Auyero, J. \& Berti, M. F. (2013). La violencia en los márgenes: Una maestra y un sociólogo en el conurbano bonaerense. Buenos Aires: Katz.

Butler, J. \& Rodríguez, F. (2006). Vida precaria: el poder del duelo y la violencia. Buenos Aires: Paidós.

Butler, J. (2010). Marcos de guerra: las vidas lloradas. Barcelona: Paidós.

Cajas Castro, J. (2009). Los desviados: cartografía urbana y criminalización de la vida cotidiana. México: Universidad Autónoma de Querétaro, Facultad de Derecho, Centro de Investigaciones Jurídicas y Criminológicas.

Caldeira, T.P. d. R. (2007). Ciudad de muros. Barcelona: Gedisa.

Ingrid CARolina Pabón SuÁRez 
Camacho, Á. \& Guzmán, Á. (1990). Ciudad y Violencia. Bogotá: Ediciones Foro Nacional.

Centro de Estudios y Análisis de Convivencia y Seguridad Ciudadana. (2012). Balance muertes violentas y delitos de mayor impacto enero-agosto años 2013-2014. Bogotá: Alcaldía Mayor.

Centro de Estudios y Análisis de Convivencia y Seguridad Ciudadana. (2015). Caracterización homicidio en Bogotá enero-diciembre 2011-2014. Información enviada por correo electrónico el 1 de septiembre de 2015.

Díaz, M. (2005). El nacimiento y constitución del barrio Patio Bonito y la importancia de la junta de acción comunal en su desarrollo. Una mirada comunicacional. (Trabajo de grado).Bogotá: Universidad Nacional Abierta y a Distancia.

Diógenes, G. (2011). Juventude, cultura e violência. En C. Barreira \& E. Batista (Orgs.),(In) segurança e sociedade. Campinas: Ponte editores.

Douglas, M. (1973). Pureza y peligro: un análisis de los conceptos de contaminación y tabú. Madrid: Siglo XXI.

Noticias RCN. (27 de febrero de 2014). El top 5 de los barrios más peligrosos de Bogotá [Noticiero]. Bogotá: RCN Televisión.

Caracol Radio. (22 de junio de 2011). Kennedy, una de las localidades más violentas de Bogotá [Noticiero]. Bogotá: Caracol Radio.

Colombia, Alcaldía Mayor de Bogotá. Decreto 398 de 2004, por el cual se reglamenta la Unidad de Planeamiento
Zonal (UPZ) No. 82, Patio Bonito, ubicada en la Localidad de Kennedy (15 de diciembre de 2003).

Colombia, Alcaldía Mayor de Bogotá. Decreto 469 de 2003, por el cual se revisa el Plan de Ordenamiento Territorial de Bogotá D.C. (23 de diciembre de 2003).

Colombia, Alcaldía Mayor de Bogotá. Decreto 337 de 2009, por el cual se modifican las Planchas Nos. 1, 2, y 3 que hacen parte del Decreto Distrital 398 de 2004, Unidad de Planeamiento Zonal (UPZ) No. 82 Patio Bonito, de la Localidad No.08 de Kennedy en Bogotá D.C. (4 agosto de 2009).

Fedevivienda. (2004). Desandar caminos construir vida: Historia del poblamiento de Patio Bonito. Bogotá: Fedevivienda.

Feltrán, Gabriel. (2011). Fronteiras de Tensão: politica e violência nas periferias de São Paulo. São Paulo: Ed. UNESP.

García, B. \& Guerrero, J. (2011). Violencia escolar en Bogotá: una mirada desde las familias, los maestros y los jóvenes. Aplicación de un modelo cualitativo de intervención y prevención de violencia en escuela, familia y barrio. Bogotá: Universidad Distrital Francisco José de Caldas \& Universidad Pedagógica y Tecnológica de Colombia y Colciencias.

Foucault, M. (2001). Los anormales: curso en el Collège de France (1974-1975). México: FCE.

Goffman, E. (1971). Estigma: la identidad deteriorada. Buenos Aires: Amorrortu Editores. territarias 36 107 
Hospital del Sur. (2013). Diagnóstico local con participación social 2012. Bogotá: Alcaldía Mayor de Bogotá.

Jimeno, M. (2010). La emergencia del investigador ciudadano: estilos de antropología colombiana. En Tocancipá, J. (Ed.). La formación del Estado Nación y las disciplinas sociales en Colombia (pp. 157-190). Popayán: Taller editorial.

Jimeno, M. \& Arias, D. (2011). La enseñanza de la antropología "propia" en América Latina. Alteridades, 21(41), Recuperado de http://www.scielo.org. $\mathrm{mx} /$ scielo.php?script=sci_arttext\&pid $=$ S0188-70172011000100002

Jimeno, M., Roldán, I., Ospina, D., Jaramillo, L., Calvo, J. \& Chaparro, S. (1996). Las sombras arbitrarias: violencia y autoridad en Colombia. Bogotá: Editorial Universidad Nacional.

La zona más violenta de Bogotá ( 15 de julio del 2016), El Tiempo. Recuperado de http://www.eltiempo.com/archivo/ documento/MAM-2100791

Pabón, C. (2015). "Limpieza social” en Bogotá. La construcción del indeseable. (Tesis de maestría). Universidad $\mathrm{Na}$ cional de Colombia, Bogotá. Disponible en http://www.bdigital.unal.edu. co/52143/1/1032360289.2016.pdf

Pabón, C. (2016). Las narrativas de desprecio: el sujeto "ñero" y la "limpieza social” en Bogotá. En M. Jimeno, C. Pabón, D. Varela \& I., Díaz. (Eds.). Etnografías contemporáneas III: el uso de la narrativa en la investigación antro-

\section{territarias 36} pológica (pp. 217-237). Bogotá: Cen- tro de Estudios Sociales, Universidad Nacional de Colombia.

Perea, C. (2015). Limpieza social. Una violencia mal nombrada. Bogotá: Centro Nacional de Memoria Histórica, Universidad Nacional de Colombia.

Policía Metropolitana de Bogotá. (2015). Delitos ocurridos de Bogotá por UPZ años 2011-2013. Informe enviado por correo electrónico el 11 de septiembre de 2016.

Ordoñez, J. P. (1996). Ningún Ser Humano es Desechable. "Limpieza social", Derechos Humanos y Orientación Sexual en Colombia. Madrid: SODEPAZ.

Pedraza, Z. (2001). Higiene y órdenes sociales en Colombia. En R. Suárez (Comp.), Reflexiones en Salud: Una aproximación desde la Antropología. Bogotá: Uniandes.

Pinzón, N. (2007). Los jóvenes de la "loma": Altos de Cazucá y el paramilitarismo en la periferia Bogotana. Maguaré (21), 271-295.

Rocha, M. (2009). Estado de derecho, seguridad y marginalidad: Representaciones en prensa sobre el fenómeno de la Limpieza social en Colombia 1988-1996. (Tesis de Maestría). Pontificia Universidad Javeriana, Bogotá. Recuperado de www.javeriana.edu.co/biblos/tesis/ csociales/tesis48.pdf

Rojas, C. E. (1996). La violencia llamada "Limpieza social". Santafé de Bogotá: CINEP.

Rojas, J. (1981). Factores determinantes en la formación estructural de un barrio 
marginal. (Trabajo de campo), Universidad Nacional de Colombia, Bogotá.

Secretaría Distrital de Planeación. (2011).

Diagnóstico de los aspectos físicos, demográficos y socioeconómicos Localidad No. 8 Kennedy. Bogotá: Alcaldía Mayor.

Serrano, A. (26 de enero de 2016). Seis zonas ponen más de la mitad de las muertes violentas en Bogotá. El Tiempo. Recuperado de http://www.eltiempo. com/bogota/zonas-con-el-mayor-numero-de-muertes-violentas-en-bogota/16492941

Stannow, L. (1996). "Limpieza social" en Colombia. (Tesis de maestría sin publi- car), Simon Fraser University, Columbia Británica

Zambrano, I. (2014). Narrativas sobre el gamín en Colombia: nuestra novela de desprecio. Uni-pluri/versidad, 14(3), 59-69.

Zambrano, I. \& Marchi, R. de C. (jul-dic, 2014). La "limpieza social" en la construcción de la infancia moderna: aproximación teórica e histórica sobre los niños en situación de calle en Brasil y Colombia. Anuario de Historia Regional y de las Fronteras, 20(1), 19-40. 
